\title{
Thiazolidinediones improve insulin sensitivity in adipose tissue and reduce the hyperlipidaemia without affecting the hyperglycaemia in a transgenic model of type 2 diabetes
}

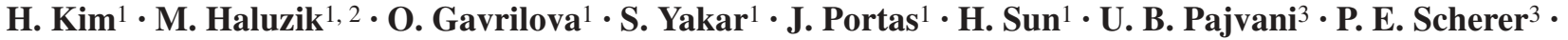 \\ D. LeRoith ${ }^{1}$ \\ ${ }^{1}$ Molecular and Cellular Physiology Section, Diabetes Branch, National Institute of Diabetes and Digestive and Kidney Diseases \\ (NIDDK), National Institutes of Health, Bethesda, USA \\ 2 3rd Department of Medicine, 1st Faculty of Medicine, Charles University, Prague, Czech Republic \\ ${ }^{3}$ Department of Cell Biology, Albert Einstein College of Medicine, Bronx, New York, USA
}

\section{Abstract}

Aim/hypothesis. The aim of this study was to examine the effects of thiazolidinediones on the MKR mouse model of type 2 diabetes.

Methods. Six-week-old wild-type (WT) and MKR mice were fed with or without rosiglitazone or pioglitazone for 3 weeks. Blood was collected from the tail vein for serum biochemistry analysis. Hyperinsulinaemic-euglycaemic clamp analysis was performed to study effects of thiazolidinediones on insulin sensitivity of tissues in MKR mice. Northern blot analysis was performed to measure levels of target genes of PPAR $\gamma$ agonists in white adipose tissue and hepatic gluconeogenic genes. Results. Thiazolidinedione treatment of MKR mice significantly lowered serum lipid levels and increased serum adiponectin levels but did not affect levels of blood glucose and serum insulin. Hyperinsulinaemic-euglycaemic clamp showed that whole-body insulin sensitivity and glucose homeostasis failed to improve in MKR mice after rosiglitazone treatment. Insulin suppression of hepatic endogenous glucose production failed to improve in MKR mice following rosiglitazone treatment. This lack of change in hepatic insulin insensitivity was associated with no change in the ratio of HMW : total adiponectin, hepatic triglyceride content, and sustained hepatic expression of PPAR $\gamma$ and stearoyl-CoA desaturase $1 \mathrm{mRNA}$. Interestingly, rosiglitazone markedly enhanced glucose uptake by white adipose tissue with a parallel increase in CD36, aP2 and GLUT4 gene expression.

Conclusions/interpretation. These data suggest that potentiation of insulin action on tissues other than adipose tissue is required to mediate the antidiabetic effects of thiazolidinediones in our MKR diabetic mice.

Keywords Adiponectin - Adipose tissue .

Hyperinsulinaemic-euglycaemic clamp · Insulin sensitivity · Muscle insulin action - Thiazolidinediones
Received: 5 April 2004 / Accepted: 15 July 2004

Published online: 15 December 2004

C) Springer-Verlag 2004

D. LeRoith ( $)$

Molecular and Cellular Physiology Section, Diabetes Branch,

National Institute of Diabetes and Digestive and Kidney

Diseases (NIDDK), National Institutes of Health,

9000 Rockville Pike, Bldg. 10, Room 8D12, Bethesda,

MD 20892-1758, USA

E-mail: Derek@helix.nih.gov

Tel.: +1-301-4968090, Fax: +1-301-4804386

Abbreviations: aP2, a cytosolic fatty acid binding protein . EGP, endogenous glucose production - G-6-P, glucose-6phosphatase $\cdot$ HMW, high molecular weight $\cdot$ IGF-1R, IGF-1 receptor $\cdot$ LMW, low molecular weight $\cdot$ PEPCK, phosphoenolpyruvate carboxykinase $\cdot$ PPAR, peroxisome proliferator activated receptor $\cdot \mathrm{SCD}$, stearoyl-CoA desaturase $\cdot$ TZDs, thiazolidinediones $\cdot$ WT, wild-type

\section{Introduction}

Impaired insulin action on skeletal muscle glucose uptake, adipocyte lipolysis and suppression of endogenous glucose production are typical characteristics of type 2 diabetic subjects. Both insulin resistance and impaired beta cell function lead to the development of this disorder.

Thiazolidinediones (TZDs), agonists for peroxisome proliferator-activated receptor (PPAR) $\gamma$, are commonly used as antidiabetic agents and improve hyperglycaemia by enhancing insulin sensitivity at the target tissues $[1,2,3]$. TZDs lower circulating and tissue lipid (triglyceride and NEFA) levels, improve glucose uptake and utilization by muscle, and reduce hepatic glucose production $[4,5,6,7,8]$. TZDs stimu- 
late adipocyte differentiation [9] and induce the formation of small adipose cells that are more sensitive to insulin than large adipose cells [10]. Both the redistribution of NEFAs and triglyceride to adipocytes from peripheral tissues and regulation of adipocyte-releasing factors have been suggested to be involved in the indirect effects of TZDs on improvement of insulin action on liver and skeletal muscle [11]. TZD treatment in A-ZIP/F-1 mice improved insulin sensitivity in muscle by reducing lipid levels but insulin sensitivity deteriorated in the liver in association with increased lipid content [12]. However, TZDs may have direct effects on muscle cells in vitro as demonstrated by increased glucose uptake of cultured L6 muscle cells [13]. TZDs improved glucose and lipid profiles in lipoatrophic patients and mice [14, 15], suggesting direct effects of TZDs on liver and skeletal muscle in vivo.

We have developed a type 2 diabetic mouse model by overexpressing a dominant-negative IGF-1 receptor (IGF-1R) in skeletal muscle (MKR mice) [16]. These mice showed impaired insulin and IGF-1 receptor signalling pathways in skeletal muscle due to hybrid formation of the mutated IGF-1R with the endogenous IGF-1 and insulin receptors. This defect in skeletal muscle resulted in insulin resistance in adipose tissue and liver, beta cell dysfunction and hyperglycaemia, leading eventually to type 2 diabetes. Significantly elevated serum lipids (NEFA and triglycerides) and increased lipid content in liver and muscle were associated with the development of the severe insulin resistance and appearance of diabetes in MKR mice [17].

Skeletal muscle is responsible for $\sim 80 \%$ of insulinstimulated whole-body glucose uptake during the hyperinsulinaemic-euglycaemic clamp in humans [18]. Thus, improved insulin sensitivity in skeletal muscle is considered to account for enhanced whole-body glucose disposal with TZD treatment [2]. TZDs enhanced insulin sensitivity in skeletal muscle by potentiation of insulin receptor signalling in Zucker obese rat and type 2 diabetic subjects as well as in cultured skeletal muscle cells $[19,20,21]$. However, in vivo physiological relevance of potentiation of insulin action on skeletal muscle in the effects of TZDs has not been fully evaluated. Muscle-specific PPAR $\gamma$ knockout mice retained intact insulin action on skeletal muscle and improved diet-induced hyperinsulinaemia in response to TZD treatment, indicating that skeletal muscle PPAR $\gamma$ is not necessary for the antidiabetic effect of TZDs [22]. In contrast, another recent study reported an important role of the muscle PPAR $\gamma$ in the insulin resistance and the antidiabetic action of TZDs [23].

In this study, we treated MKR mice with PPAR $\gamma$ agonists, rosiglitazone and pioglitazone, to clarify the significance of insulin action on skeletal muscle in the antidiabetic effects of TZDs. Our data suggest that im- proved lipid profiles and insulin action on adipose tissue with PPAR $\gamma$ activation were not sufficient to reduce the hyperglycaemia in MKR mice that maintain defective insulin signalling pathways in skeletal muscle.

\section{Methods}

Animals. The generation and characterization of MKR mice have been previously described [16]. Homozygous MKR male mice (FVB/N background) used for the current study were subjected to Southern blot analysis for genotyping as described before [16]. Six-week-old male wild-type (WT) and MKR mice were fed powder-type diets (AIN-93G [Dyets, Bethlehem, Pa., USA]) with or without rosiglitazone (12 mg/kg diet) or pioglitazone $(80 \mathrm{mg} / \mathrm{kg}$ diet $)$ for 3 weeks. Both rosiglitazone and pioglitazone treatments were mixed with the powder-type diet using a coffee grinder. C57BL/6J-lep ${ }^{o b / o b}$ male mice were obtained from the Jackson Laboratory (Bar Harbor, Me., USA). Mice were maintained on a 12-h light/dark cycle and all experiments were performed in agreement with National Institutes of Health guidelines and with the approval of the Animal Care and Use Committee of the National Institute of Diabetes and Digestive and Kidney Diseases. All mice were killed after anaesthesia using $2.5 \%$ Avertin at $15-17 \mu \mathrm{l} / \mathrm{g}$ body weight in the non-fasting state between 10.00 hours and noon. Blood was collected from the tail vein and a Glucometer (One Touch II; LifeScan, Milpitas, Calif., USA) was used to measure glucose levels in the non-fasting state. Tissues were collected and immediately frozen in liquid nitrogen for RNA and protein extraction and measurement of tissue triglyceride levels.

Serum analysis. Serum was obtained from the tail vein between 10.00 hours and 12.00 hours in the non-fasting state. Serum NEFA and triglyceride levels were measured using a Fatty acid assay kit (Roche, Indianapolis, Ind., USA) and GPO-Trinder kit (Sigma, St. Louis, Mo., USA), respectively. Serum insulin levels were determined using a radioimmunoassay kit (Linco Research, St. Charles, Mo., USA). Distribution of the size of serum adiponectin was measured as described previously [24].

Hyperinsulinaemic-euglycaemic clamp. The hyperinsulinaemic-euglycaemic clamp was performed based on the protocol developed by Kim et al. [25]. Wild-type and MKR mice were treated or not treated with rosiglitazone for 3 weeks. Then, mice were anaesthetised with ketamine $(100 \mathrm{mg} / \mathrm{kg})$ and xylazine $(10 \mathrm{mg} / \mathrm{kg})$. A Silastic catheter (inside diameter $0.30 \mathrm{~mm}$, outside diameter $0.64 \mathrm{~mm}$; Dow Corning, Midland, Mich., USA) filled with heparin solution (100 USPU/ml in $0.9 \% \mathrm{NaCl}$ ) was inserted via a right lateral neck incision and advanced into the superior vena cava via the right internal jugular vein. The catheter was sutured into place according to the procedure of MacLeod and Shapiro [26]. The distal end of the catheter was knotted, tunnelled subcutaneously, exteriorised first at the dorsal cervical midline, and then further tunnelled subcutaneously and exteriorised in the dorsal midline, $2 \mathrm{~cm}$ above the tail. A silk suture was fastened around the catheter at the neck site. The clamps were then performed 4 to 5 days later after complete recovery of the animals from the operation. Clamps began at 07.00 hours and were performed in mice fasted for $12 \mathrm{~h}$. Mice were placed into a restrainer (552-BSRR; Plas-Labs, Lansing, Mich., USA) and the catheter was externalised. The tip of the tail was cut before the start of the first infusion and all subsequent blood collections were carried out 
using this site. Blood was collected into heparinised microhaematocrit capillary tubes (Fisher Scientific, Pittsburgh, Pa., USA) and centrifuged for $10 \mathrm{~s}$ to obtain plasma. The basal rates of glucose turnover were measured by continuous infusion of $\left[3-{ }^{3} \mathrm{H}\right]$ glucose $(0.74 \mu \mathrm{Bq} / \mathrm{min})$ for $120 \mathrm{~min}$ starting at 07.00 hours. Blood samples $(20 \mu \mathrm{l})$ were collected at $90 \mathrm{~min}$ and $115 \mathrm{~min}$ of the basal period to determine plasma $\left[{ }^{3} \mathrm{H}\right]$ glucose concentration. A 120-min hyperinsulinaemic-euglycaemic clamp was started at 09.00 hours. Insulin was continuously infused at the rate of $2.5 \mathrm{mU} \cdot \mathrm{kg}^{-1} \cdot \mathrm{min}^{-1}$ (Humulin R; Eli Lilly, Indianapolis, Ind., USA). During the clamp study, blood samples $(20 \mu \mathrm{l})$ were taken from the tail vein at 15 -min intervals for the immediate measurement of plasma glucose concentration, and $20 \%$ glucose was infused at variable rates to maintain plasma glucose at basal glucose concentrations. Insulin-stimulated whole-body glucose flux was estimated using a continuous infusion of HPLC-purified $\left[3-{ }^{3} \mathrm{H}\right]$ glucose (370 $\mu \mathrm{Bq}$ bolus, $3.7 \mu \mathrm{Bq} / \mathrm{min}$; NEN Life Science Products, Boston, Mass., USA) during the clamps. To estimate insulinstimulated glucose transport activity of skeletal muscle, white and brown adipose tissue, 2 -deoxy-D-[1-14 C $]$ glucose $\left(2-\left[{ }^{14} \mathrm{C}\right]\right.$ DG1; NEN Life Science, Boston, Mass., USA) was injected as a bolus $(370 \mathrm{~Bq}) 45 \mathrm{~min}$ before the end of the clamps. Blood samples $(20 \mu \mathrm{l})$ were taken $80,85,90,100,110$ and $120 \mathrm{~min}$ after the beginning of the clamps for the determination of plasma $\left[{ }^{3} \mathrm{H}\right]$ glucose, 2-[ $\left.{ }^{14} \mathrm{C}\right] \mathrm{DG}$ and ${ }^{3} \mathrm{H}_{2} \mathrm{O}$ concentrations. Additional blood samples $(10 \mu \mathrm{l})$ were taken before the start and at the end of the clamp studies for measurement of plasma insulin concentration. All infusions were performed using microdialysis pumps (CMA/Microdialysis, Acton, Mass., USA). At the end of the clamp period, animals were anaesthetised by ketamine and xylazine injection. Gastrocnemius muscles from hindlimbs, epididymal and brown adipose tissue and liver were collected and frozen immediately using liquid $\mathrm{N}_{2}$-cooled aluminium blocks, and stored at $-70^{\circ} \mathrm{C}$ for later analysis.

Calculations. Basal endogenous glucose production was calculated as the ratio of the pre-clamp $\left[3-{ }^{3} \mathrm{H}\right]$ glucose infusion rate (disintegrations per minute $[\mathrm{dpm}]$ ) to the specific activity of the plasma glucose (mean of the values in the 90 and 115 min of the basal pre-clamp period, in $\mathrm{dpm} / \mu \mathrm{mol})$. Clamp wholebody glucose uptake was calculated as the ratio of the $\left[3-{ }^{3} \mathrm{H}\right]$ glucose infusion rate $(\mathrm{dpm} / \mathrm{min})$ to the specific activity of plasma glucose $(\mathrm{dpm} / \mu \mathrm{mol})$ during the last $30 \mathrm{~min}$ of the clamp (mean of the 90-120 min samples). Whole-body glycolysis was determined from the rate of increase in plasma ${ }^{3} \mathrm{H}_{2} \mathrm{O}$ determined by linear regression using the 80-120 min points. Plasma ${ }^{3} \mathrm{H}_{2} \mathrm{O}$ concentrations were measured from the difference between non-dried vs dried plasma ${ }^{3} \mathrm{H}$ counts. Clamp endogenous glucose production was determined by subtracting the average glucose infusion rate in the last $30 \mathrm{~min}$ of clamp from the whole-body glucose uptake. Whole-body glycogen and lipid synthesis was estimated by subtracting the wholebody glycolysis from the whole-body glucose uptake, which assumes that glycolysis and glycogen/lipid synthesis account for the majority of insulin-stimulated glucose uptake [27]. Muscle and white and brown adipose tissue glucose uptake was calculated from the plasma 2-deoxy-D-[1-14C] glucose concentration profile (using plasma ${ }^{14} \mathrm{C}$ counts at $80-120 \mathrm{~min}$, the area under the curve was calculated by trapezoidal approximation) and tissue 2-deoxy-D-[1-14C] glucose-6-phosphate content as described previously [28].

Tissue triglyceride content determination. Liver and quadriceps muscle were powdered and tissue triglycerides were extracted in chloroform/methanol solution. The solution was centrifuged after adding $2 \% \mathrm{KH}_{2} \mathrm{PO}_{4}$ and the lower phase was collected for evaporation. Isopropyl alcohol was then added to dissolve the remaining pellet. The amount of released glycerol was measured by radiometric assay as described previously $[15,29]$.

Northern blot analysis. TRIzol reagent (Life Technologies, Rockville, Md., USA) was used to isolate total RNA, and northern blot analysis was performed as described previously [30]. Signals were quantified using densitometry (Epson Perfection Scanner 1640SU) and the MACBas version 2.52 program (Fuji Photo Film, Tokyo, Japan).

Western blot analysis. $150 \mu \mathrm{g}$ of protein extracted from livers was used for western blot analysis as described before [31], using insulin receptor $\beta$ antibody (Santa Cruz Biotechnology, Inc. Santa Cruz, Calif., USA) and $\beta$-actin antibody (Sigma, St. Louis, Mo., USA). Bands were quantified by densitometry (Epson Perfection Scanner 1640SU) using the MACBas version 2.52 program. The amount of insulin receptor protein was determined by normalisation with $\beta$-actin levels in each sample.

Statistical analysis. All data are expressed as means \pm SE. Student's $t$ test (unpaired and paired) was used to determine statistically significant differences between genotypes.

\section{Results}

TZD treatment improves serum lipid profile but not hyperglycaemia in MKR mice. Treating MKR mice with rosiglitazone for 3 weeks significantly lowered the elevated serum lipid levels to normal (Fig. 1a, b). Serum NEFA levels fell from $0.7 \pm 0.03$ to $0.5 \pm 0.02 \mathrm{mmol} / \mathrm{l}$ in MKR mice after treatment $(p<0.001)$ (Fig. 1a) while serum triglycerides fell from $2.8 \pm 0.4$ to $1.4 \pm 0.1 \mathrm{mmol} / \mathrm{l}(p<0.003)$ (Fig. $1 \mathrm{~b})$. In contrast, serum lipid levels remained unchanged in WT mice following treatment (Fig. 1a, b). Following rosiglitazone treatment there was a significant elevation $(p<0.001)$ in serum adiponectin levels in both WT and MKR mice by $70 \%$ and $73 \%$, respectively (Fig. 1c).

Rosiglitazone treatment in MKR mice for 3 weeks did not reduce glucose or insulin levels, which were increased 3.6- and seven-fold, respectively (Fig. 1d, e). Continued treatment up to 4 weeks did not affect these parameters (data not shown). In contrast, 2 weeks of rosiglitazone treatment caused a significant reduction of blood glucose levels in $o b / o b$ mice (from $8.6 \pm 0.8$ to $5.8 \pm 0.3 \mathrm{mmol} / \mathrm{l} ; p<0.02$ ), showing the effectiveness of the rosiglitazone treatment regimen.

Taken together, these results show that in MKR mice defective in insulin-signalling pathways in skeletal muscle, rosiglitazone treatment improved serum lipid profile and adiponectin levels but had no effect on the hyperglycaemia and hyperinsulinaemia.

It has been shown that, compared with rosiglitazone treatment, treatment with pioglitazone may have more beneficial effects in terms of serum triglyceride, low-density lipoprotein, and total cholesterol levels in 
a

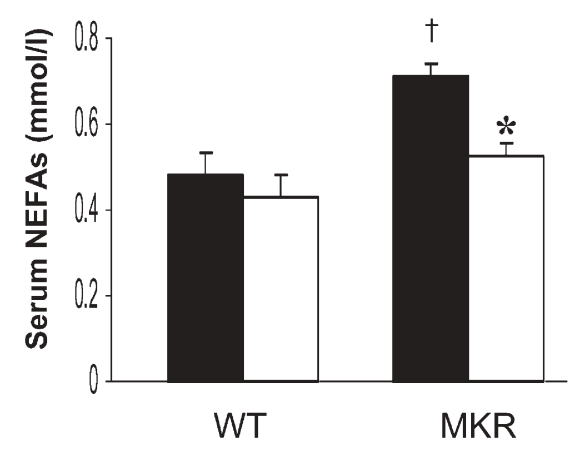

d

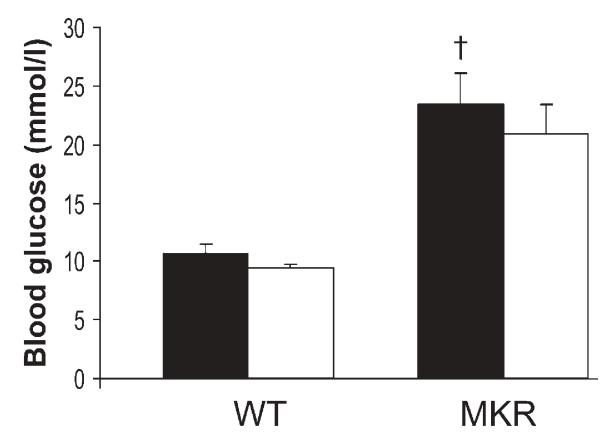

Fig. 1. Effect of rosiglitazone treatment on serum NEFA (a), triglyceride (b), adiponectin (c), blood glucose (d) and serum insulin (e) levels in WT and MKR mice. Six-week-old MKR and WT mice were treated with (white bars) or without (black bars) rosiglitazone for 3 weeks. In the non-fasting state, blood

e
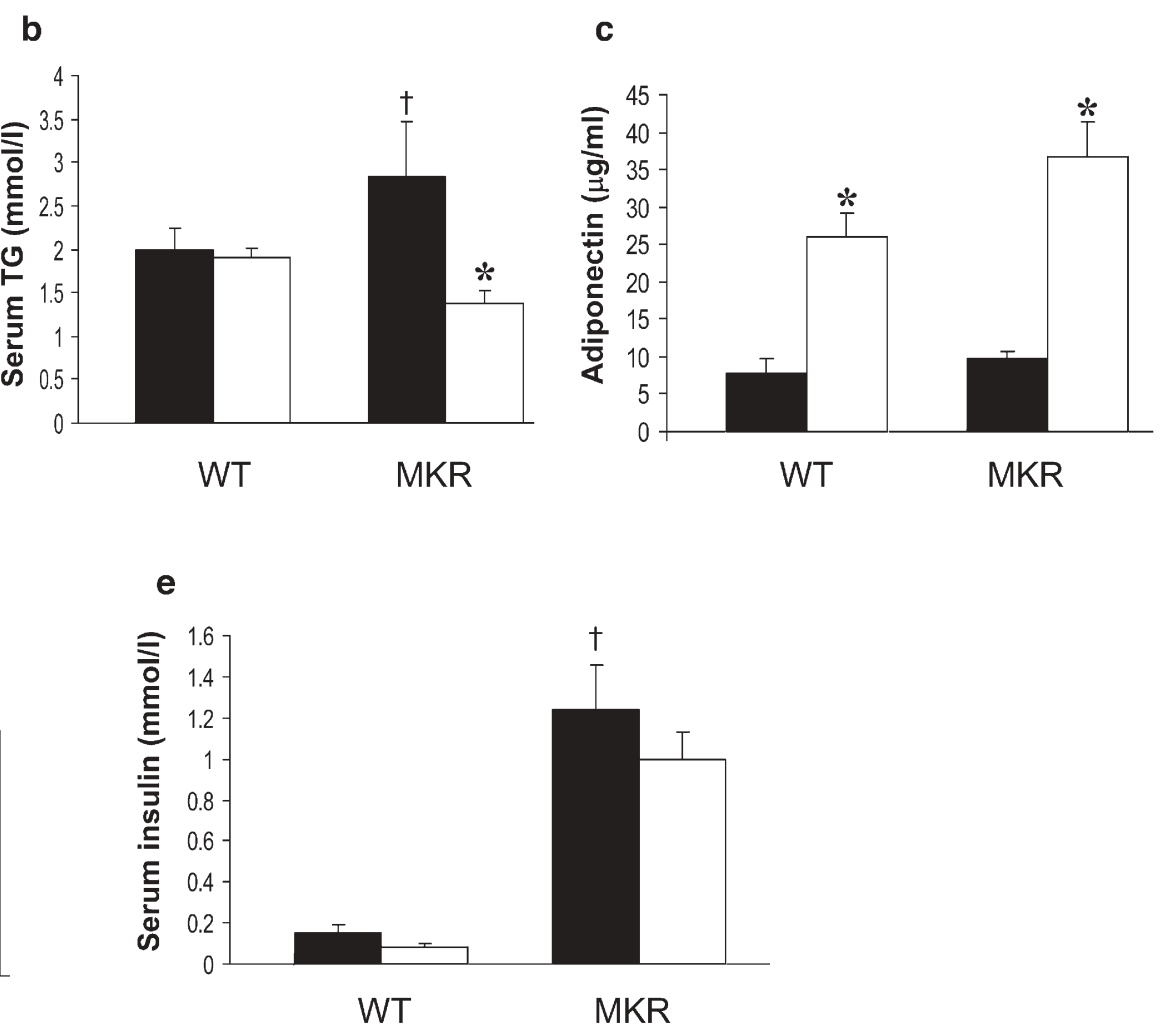

or serum was collected for analysis. Data are expressed as means $\pm \mathrm{SE}$ ( $n=6-8$ in each group). * Indicates significant differences between treated and untreated group at $p<0.05$. $\dagger p<0.05$ vs WT; TG, triglycerides

Table 1. Effect of pioglitazone treatment on metabolic parameters

\begin{tabular}{|c|c|c|c|c|}
\hline & WT & WT+Pio & MKR & MKR+Pio \\
\hline Body weight (g) & $27.7 \pm 1.3$ & $26.3 \pm 1.2$ & $20.3 \pm 0.6^{\dagger}$ & $22.9 \pm 0.9^{*}$ \\
\hline Combined epididymal and inguinal adipose tissue weight (g) & $1.1 \pm 0.18$ & $0.7 \pm 0.18$ & $0.5 \pm 0.06^{\dagger}$ & $0.7 \pm 0.02^{*}$ \\
\hline Insulin $(\mathrm{mmol} / \mathrm{l})$ & $0.1 \pm 0.01$ & $0.1 \pm 0.01$ & $2.0 \pm 0.8^{\dagger}$ & $1.8 \pm 0.5$ \\
\hline NEFAs (mmol/l) & $0.4 \pm 0.05$ & $0.3 \pm 0.05$ & $0.8 \pm 0.14^{\dagger}$ & $0.4 \pm 0.02 *$ \\
\hline Triglyceride (mmol/l) & $1.0 \pm 0.1$ & $0.9 \pm 1.0$ & $1.6 \pm 0.2^{\dagger}$ & $0.7 \pm 0.1^{*}$ \\
\hline
\end{tabular}

Six-week-old male WT and MKR mice were fed a diet with or without pioglitazone for 3 weeks. Blood samples and adipose tissues were collected in the non-fasting state for analysis. Data are expressed as means \pm SE $(n=6-7)$. Triglycerides (TG)

type 2 diabetic subjects [32], possibly related to its additional activation of the PPAR $\alpha$ receptor. To examine the effect of pioglitazone, MKR mice were treated with pioglitazone for 3 weeks. Pioglitazone treatment in MKR mice caused 1.4-fold elevated adipose tissue weight compared with untreated MKR mice (Table 1). Pioglitazone treatment was unable to reduce glucose and insulin levels but significantly lowered serum NEFAs (from $0.8 \pm 0.14$ to $0.4 \pm 0.02 \mathrm{mmol} / \mathrm{l} ; p<0.02$ ) and triglyceride (from $1.6 \pm 0.2$ to $0.7 \pm 0.1 \mathrm{mmol} / \mathrm{l}$; $p<0.02$ ) levels (Table 1 ), similar to the effects seen in MKR mice after rosiglitazone treatment (Fig. 1). and NEFAs were measured in a separate assay from those in the rosiglitazone treatment. *Significant difference within genotype between treated and untreated groups $(p<0.05) ; p<0.05$ vs WT

Rosiglitazone treatment improves insulin sensitivity in white adipose tissue in MKR mice. To explain the lack of hypoglycaemic effect of TZDs on MKR mice, we performed hyperinsulinaemic-euglycaemic clamp studies after 3 weeks of rosiglitazone treatment. After fasting for $12 \mathrm{~h}$, basal blood glucose and insulin levels were not affected by treatment in both WT and MKR mice (Table 2). Glucose infusion rate did not differ in treated and untreated groups of both genotypes (Table 2). The values for whole-body glucose uptake, whole-body glycolysis and whole-body glycogen synthesis, reflecting whole-body glucose fluxes, remained 
Table 2. Effects of rosiglitazone treatment on metabolic parameters during basal and hyperinsulinaemic-euglycaemic clamp

\begin{tabular}{|c|c|c|c|c|}
\hline & WT & $\mathrm{WT}+\mathrm{R}$ & MKR & $\mathrm{MKR}+\mathrm{R}$ \\
\hline Mouse no. & 5 & 5 & 6 & 6 \\
\hline Body weight (g) & $26.5 \pm 1.1$ & $28.1 \pm 1.2$ & $18.4 \pm 0.5^{\dagger}$ & $19.6 \pm 0.5$ \\
\hline Basal insulin (mmol/l) & $0.1 \pm 0.03$ & $0.1 \pm 0.02$ & $0.2 \pm 0.03$ & $0.1 \pm 0.12$ \\
\hline Basal EGP $\left(\mu \mathrm{mol} \cdot \mathrm{kg}^{-1} \cdot \mathrm{min}^{-1}\right)$ & $124 \pm 9.5$ & $112 \pm 5.8$ & $178 \pm 12^{\dagger}$ & $142 \pm 13$ \\
\hline Clamp blood glucose $(\mathrm{mmol} / \mathrm{l})$ & $7.3 \pm 0.2$ & $6.9 \pm 0.1$ & $9.6 \pm 0.6^{\dagger}$ & $9.6 \pm 0.5$ \\
\hline Glucose infusion rate $\left(\mu \mathrm{mol} \cdot \mathrm{kg}^{-1} \cdot \mathrm{min}^{-1}\right)$ & $159 \pm 40$ & $199 \pm 16$ & $0 \pm 0^{\dagger}$ & $16.7 \pm 9.8$ \\
\hline Whole-body glucose uptake $\left(\mu \mathrm{mol} \cdot \mathrm{kg}^{-1} \cdot \mathrm{min}^{-1}\right)$ & $222 \pm 34.9$ & $233 \pm 11.3$ & $117 \pm 4.6^{\dagger}$ & $101 \pm 7.3$ \\
\hline Whole body glycolysis $\left(\mu \mathrm{mol} \cdot \mathrm{kg}^{-1} \cdot \mathrm{min}^{-1}\right)$ & $155 \pm 17.4$ & $170 \pm 11.8$ & $92.3 \pm 11.1^{\dagger}$ & $81 \pm 8.7$ \\
\hline Whole-body glycogen synthesis $\left(\mu \mathrm{mol} \cdot \mathrm{kg}^{-1} \cdot \mathrm{min}^{-1}\right)$ & $79 \pm 30$ & $63 \pm 8.7$ & $19 \pm 5.8^{\dagger}$ & $20 \pm 4.7$ \\
\hline
\end{tabular}

Six-week-old MKR and WT mice received a diet with or without rosiglitazone for 3 weeks. After $12 \mathrm{~h}$ fasting mice were subjected to the hyperinsulinaemic-euglycaemic clamp. Data are expressed as means \pm SE. $* p<0.05$ vs untreated group within genotype; ${ }^{\dagger} p<0.05$ vs WT
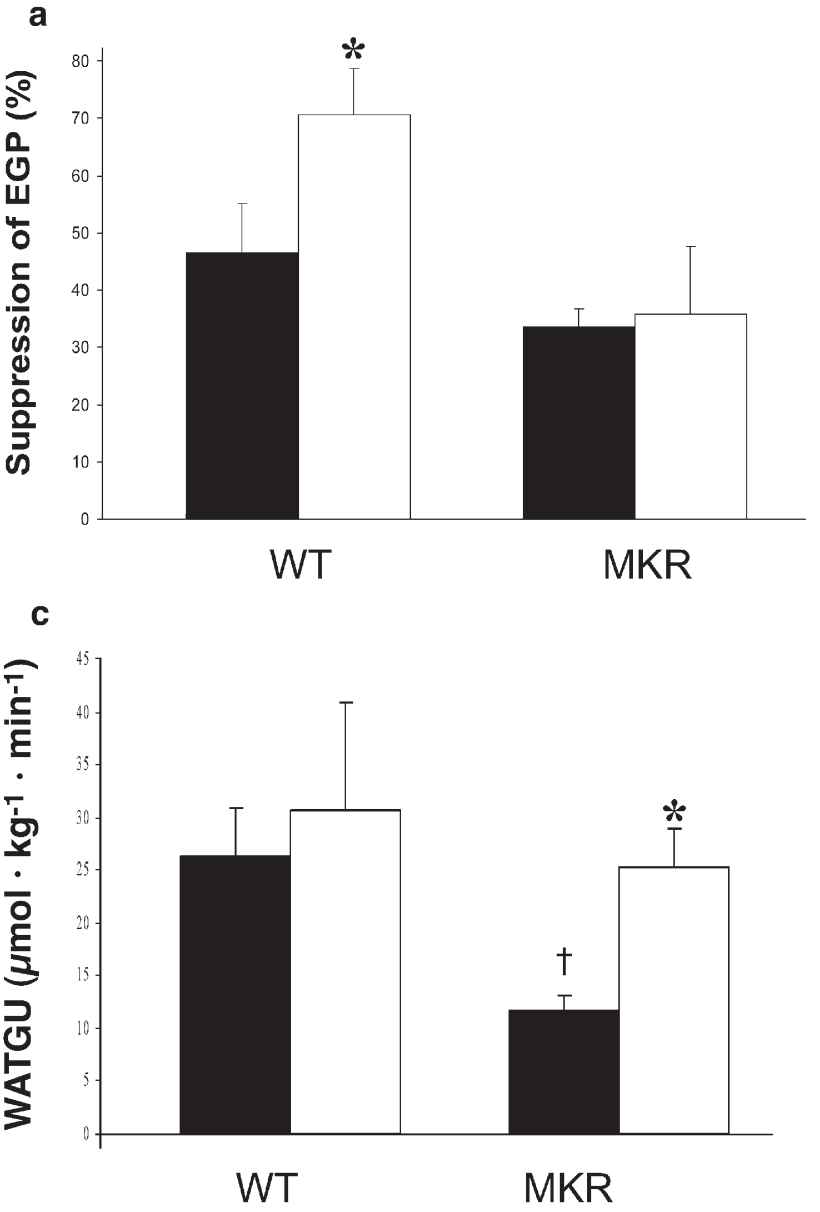

unchanged in both genotypes following rosiglitazone treatment (Table 2). These results show that rosiglitazone treatment did not change whole-body insulin sensitivity and glucose homeostasis in MKR and WT mice, confirming the lack of effect of rosiglitazone on hyperinsulinaemia and hyperglycaemia in the MKR mice.

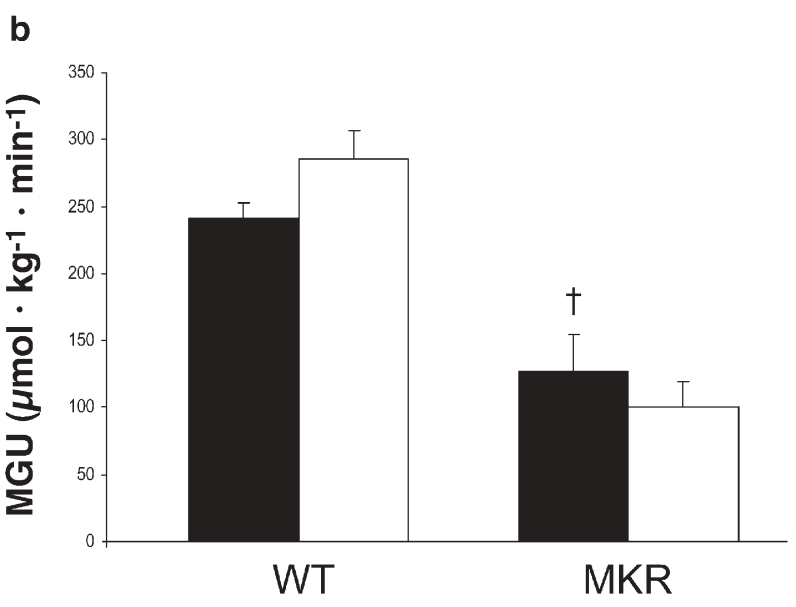

Fig. 2. Effect of rosiglitazone treatment on suppression of endogenous glucose production (EGP) (a), muscle glucose uptake (MGU) (b) and white adipose tissue glucose uptake (WATGU) (c) during hyperinsulinaemic-euglycaemic clamp analysis. Six-week-old male WT and MKR mice were treated with (white bars) or without (black bars) rosiglitazone for 3 weeks and after $12 \mathrm{~h}$ fasting mice were subjected to hyperinsulinaemic-euglycaemic clamp analysis. Data are expressed as means \pm SE $(n=5-6)$. *Significant at $p<0.05$, within genotype between untreated and treated group. ${ }^{\dagger} p<0.05$ vs WT

During the hyperinsulinaemic-euglycaemic clamp, insulin-suppressed endogenous glucose production (EGP) did not change in MKR mice following rosiglitazone treatment, indicating that liver insulin sensitivity did not differ in response to rosiglitazone treatment (Fig. 2a). In contrast, rosiglitazone treatment significantly increased suppression of EGP lev- 
a

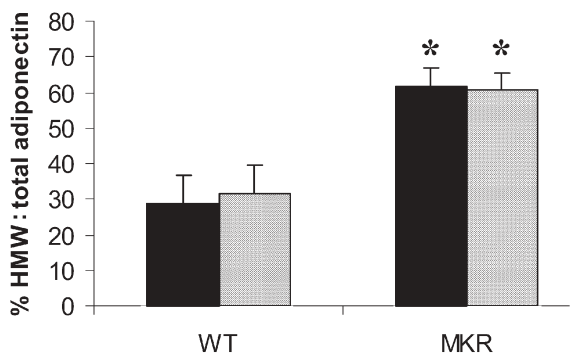

c

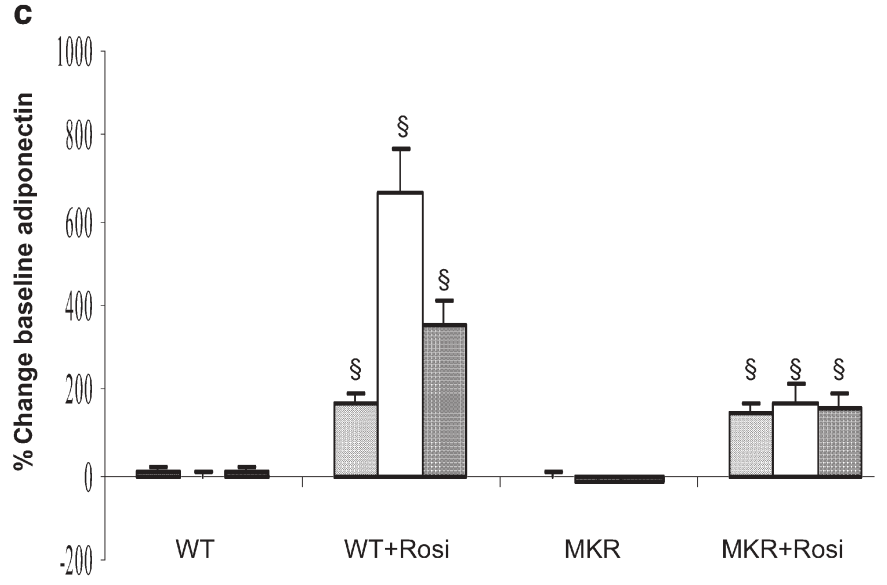

b

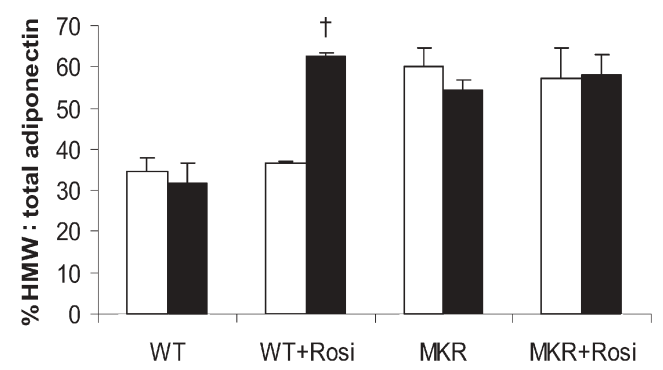

Treatment with TZD fails to increase HMW : total adiponectin ratio in MKR mice. Previously, we have found that circulating adiponectin was present in two forms [24], a low molecular weight (LMW) and a high molecular weight (HMW) complex. Furthermore, the ratio HMW : total adiponectin showed an association with improved insulin sensitivity in subjects after TZD treatment [33]. To address the failure to improve insulin sensitivity despite the significantly increased circulating adiponectin levels in MKR mice after rosiglitazone treatment, the distribution of the LMW and HMW forms of circulating adiponectin was analysed by velocity sedimentation. The ratio of HMW : total adiponectin was significantly higher (two-fold; $p<0.01)$ in MKR mice than in WT mice both at 3 and 8 weeks of age (Fig. 3a). After 3 weeks of rosiglitazone treatment, the percentage of adiponectin found in the HMW form was further increased by $70 \%$ in WT mice (from $36.8 \pm 0.4$ to $62.5 \pm 1.1 \%$; $p<0.05$ ) (Fig. 3b). Compared to the increase in HMW, the percentage increase in LMW (hexameric) adiponectin was significantly less in WT mice following rosiglitazone treatment (Fig. 3c). Consistent with the lack of TZD-mediated improvement in hepatic insulin sensitivity in MKR mice, rosiglitazone treatment did not induce any significant change in adiponectin oligomeric distribution in MKR mice (Fig. 3b, c).

Changes in gene expression following rosiglitazone treatment. A direct effect of a PPAR $\gamma$ agonist on target gene expression is one of the possible mechanisms responsible for significant improvement of insulin sensitivity in white adipose tissue of MKR mice after 

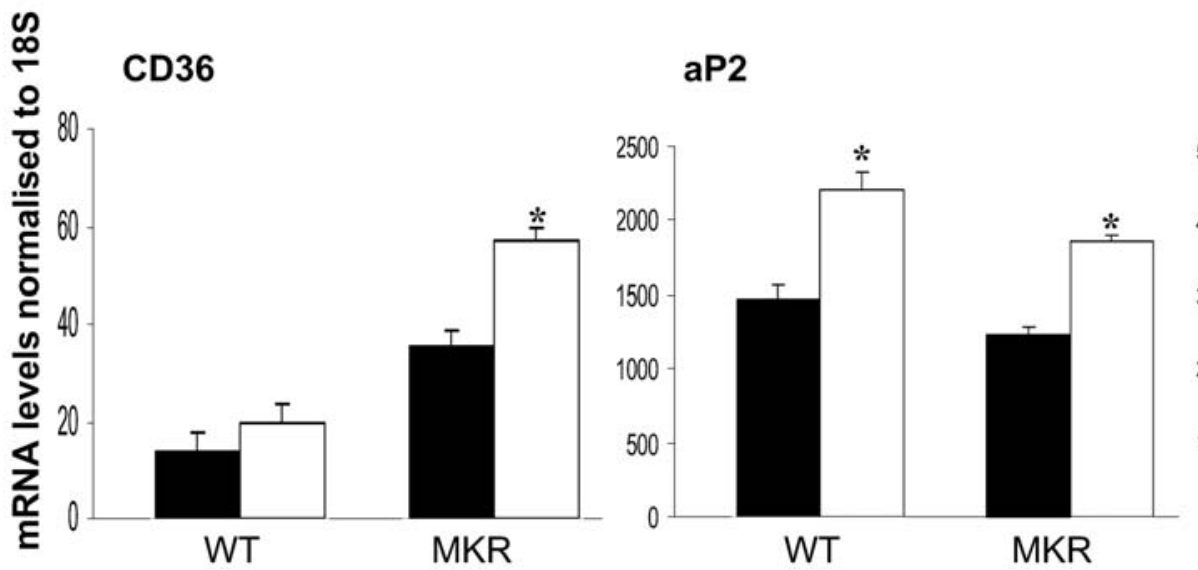

\section{GLUT4}

Fig. 4. Effect of rosiglitazone treatment on the expression of mRNA in adipose tissue. Epididymal adipose tissues were collected from mice treated with (white bars) or without (black bars) rosiglitazone for 3 weeks. mRNA levels were analysed

by northern blotting and normalised to $18 \mathrm{~S}$ mRNA. GLUT4, glucose uptake protein; aP2, fatty acid binding protein; CD36, FA uptake protein. $*$ Significant at $p<0.05$, within genotype. Data are expressed as mean $\pm \operatorname{SE}(n=6)$
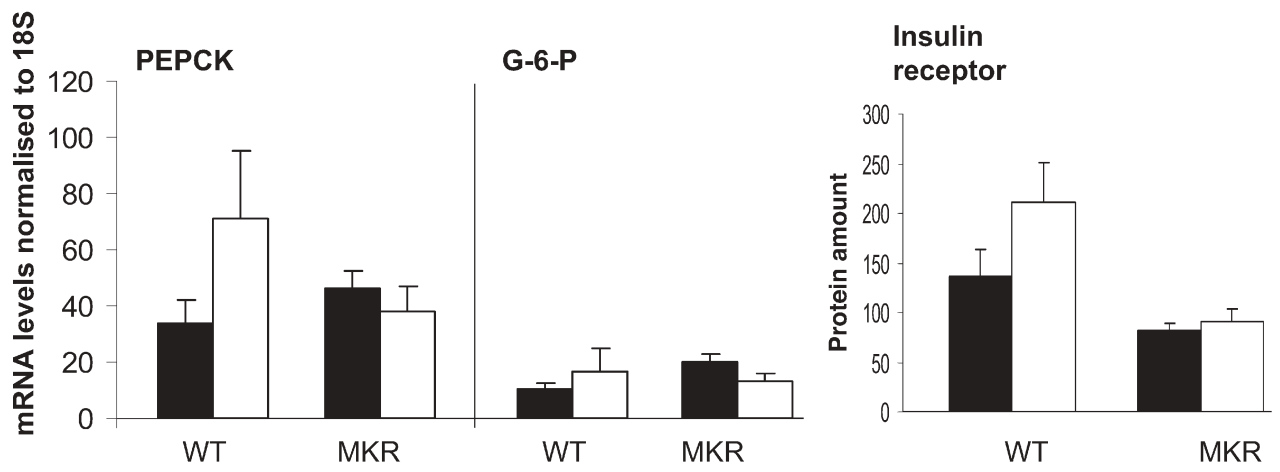

Fig. 5. Effect of rosiglitazone treatment on liver mRNA and protein expression. Livers were collected from mice treated with (white bars) or without (black bars) rosiglitazone for 3 weeks. mRNA levels were analysed by northern blotting and protein levels were analysed by western blotting. mRNA and protein expression levels were normalised to 18S mRNA and $\beta$-actin, respectively. PEPCK, phosphoenolpyruvate carboxykinase; G-6-P, glucose-6-phosphatase. Data are expressed as means $\pm \mathrm{SE}(n=6)$

rosiglitazone treatment $[34,35]$. The weight of adipose tissue (combined epididymal and inguinal adipose tissue) was significantly increased in MKR mice, but not in WT mice, in response to rosiglitazone (data not shown) and pioglitazone treatment (Table 1). We determined the levels of expression of target genes of PPAR $\gamma$ agonists such as CD36, aP2 and GLUT4 in adipose tissue after treatment. A recent study [36] suggested an important role of CD36, a fatty acid transporter, in the hypolipidaemic effects of rosiglitazone. The levels of CD36, aP2 (a cytosolic fatty acid binding protein) and GLUT4 were significantly $(p<0.05)$ increased in adipose tissue in MKR mice following rosiglitazone treatment (Fig. 4).

A previous study showed that PPAR $\gamma$ agonists inhibited the expression of genes involved in hepatic

gluconeogenic enzymes, including phosphoenolpyruvate carboxykinase (PEPCK) and glucose-6-phosphatase (G-6-P) [37]. However, in the present study the expression of PEPCK and G-6-P mRNA remained unchanged in both genotypes after treatment (Fig. 5). Furthermore, the protein levels of the insulin receptor were not significantly affected by treatment in both genotypes (Fig. 5).

Rosiglitazone treatment reduced muscle but not liver triglyceride content in MKR mice. Several studies have hypothesised that lipid influx into adipose tissue from liver and skeletal muscle following PPAR $\gamma$ activation contributes to the insulin-sensitising effects of PPAR $\gamma$ agonists $[2,11]$. To examine whether tissue lipid levels are related to the lack of effect of rosiglitazone treatment on whole-body insulin sensitivity in MKR mice, we measured triglyceride content in muscle and liver. Rosiglitazone treatment significantly decreased muscle triglyceride content towards normal in MKR mice (from $23.1 \pm 1.9$ to $14.9 \pm 2.0 \mu \mathrm{mol} / \mathrm{g}$; $p<0.01$ ) (Fig. 6a). In contrast, liver triglyceride levels were not affected by rosiglitazone treatment in both genotypes (Fig. 6b). Furthermore, pioglitazone treatment did not affect liver triglyceride content in MKR mice (data not shown). 


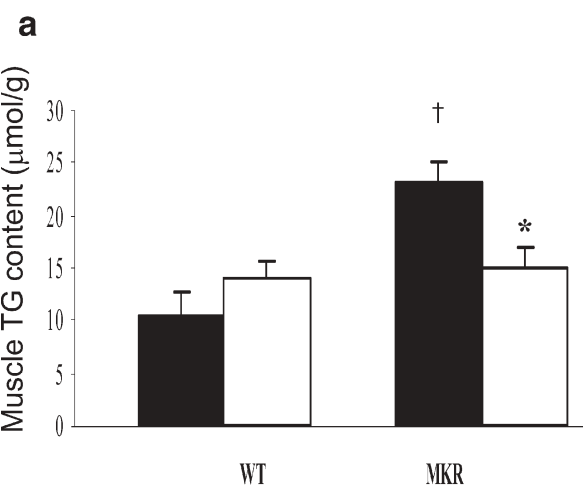

Fig. 6. Triglyceride (TG) content after rosiglitazone treatment in quadriceps muscle (a) and liver (b). In the non-fasting state, liver and quadriceps muscle were collected to measure triglyceride content from WT and MKR mice fed diet with (white

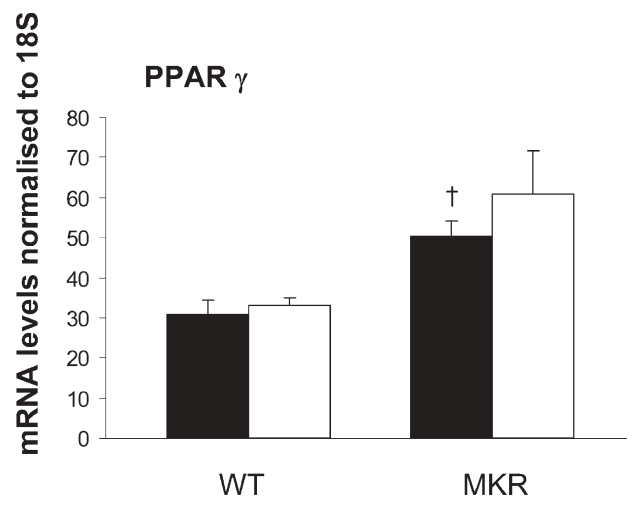

Fig. 7. Effect of rosiglitazone treatment on hepatic peroxisome proliferator-activated receptor (PPAR) $\gamma$ and stearoyl-CoA desaturase 1 (SCD-1) mRNA. Livers were removed from the mice receiving diets with (white bars) or without (black bars) rosiglitazone treatment for 3 weeks. mRNA levels were determined by northern blot analysis and the level of $18 \mathrm{~S}$ mRNA was used to normalise. Data expressed as means \pm SE. ${ }^{\dagger}$ Significant at $p<0.05$ vs WT

To elucidate the lack of effect of rosiglitazone on hepatic triglyceride content in MKR mice, the levels of gene expression involved in lipid metabolism, such as PPAR $\gamma$ and stearoyl-CoA desaturase (SCD)-1 mRNA, were determined in liver. The levels of PPAR $\gamma$ and SCD-1 mRNA in MKR mice were elevated 1.3fold and 1.9-fold, respectively, compared to WT (Fig. 7). Rosiglitazone treatment in MKR mice did not change these levels of genes (Fig. 7). The levels of PPAR $\gamma$ and SCD1 mRNA were not affected in WT mice after rosiglitazone treatment (Fig. 7). Therefore, sustained levels of these genes in MKR mice after rosiglitazone treatment may explain the lack of change in hepatic lipid content.

\section{b}

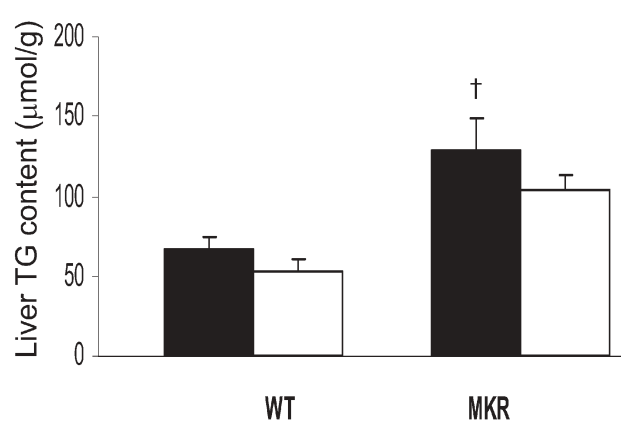

bars) or without (black bars) rosiglitazone for 3 weeks. Data are expressed as means \pm SE ( $n=6$ in each group). *Significant at $p<0.05$, within genotype; ${ }^{\dagger} p<0.05$ vs WT

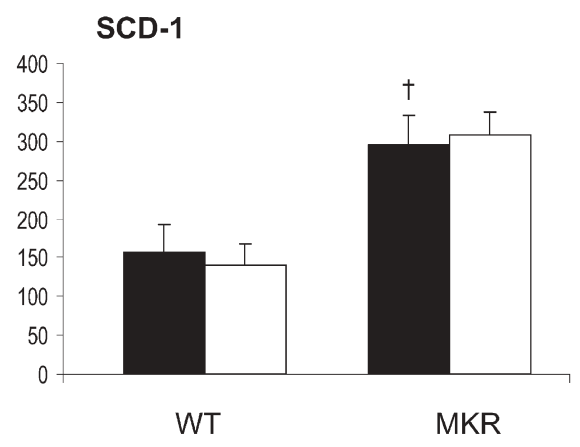

\section{Discussion}

The present study demonstrates that rosiglitazone and pioglitazone, PPAR $\gamma$ agonists, markedly improved lipid profiles, yet failed to reverse the hyperglycaemia and the hyperinsulinaemia of MKR mice that have impaired insulin and IGF-1 receptor signalling pathways in skeletal muscle. This may support the hypothesis that potentiation of insulin signalling in skeletal muscle plays a crucial role in the antidiabetic effects of TZDs. Interestingly, PPAR $\gamma$ activation in MKR mice showed significantly elevated insulin sensitivity (up to $40 \%$ of untreated group) in adipose tissue. This improvement in adipose tissue was not paralleled by a change in whole-body insulin insensitivity and glucose homeostasis, indicating that improved insulin action in tissues other than adipose tissue is required for the antidiabetic effect of TZDs.

Several studies have suggested that repartitioning of lipids away from skeletal muscle and liver contributes to improved insulin sensitivity in these tissues $[2,11]$. Ablation of the CD36 gene in mice inhibited fatty acid uptake into adipose tissue as well as skeletal muscle [38]. Moreover, in CD36-deficient rats the effect of pioglitazone is blunted [36]. In the present study, increased gene expression of CD36, a fatty acid transporter protein, and $\mathrm{aP} 2$, a fatty acid binding protein, in adipose tissue was associated with significant- 
ly increased fat weight (data not shown) in MKR mice after rosiglitazone treatment, implying more lipid influx into adipose tissue. In concert with the reduction in circulating lipid (NEFA and triglyceride) levels, muscle triglyceride content was reduced by $35 \%$ in MKR mice following rosiglitazone treatment. A recent study [39] showed increased fatty acid uptake and oxidation in cultured muscle cells following treatment with TZDs, indicating a direct role of TZDs in muscle to reduce circulating or tissue lipid levels. Moreover, a study using muscle PPAR $\gamma$-deficient mice showed a direct role of PPAR $\gamma$ in the regulation of lipid metabolism in muscle [22]. Therefore, both direct and indirect effects of TZDs could be related to the reduction of muscle triglyceride content with rosiglitazone treatment in MKR mice. This reduction in muscle triglyceride content in MKR mice following rosiglitazone treatment had no effect on muscle insulin insensitivity. Our previous study reported a significant reduction (of $\sim 90 \%$ ) of insulin-stimulated glucose uptake in MKR skeletal muscle studied ex vivo due to hybrid receptor formation between the mutant and endogenous IGF-1 receptors, and insulin receptors [16]. Thus, these defects may account for muscle insulin insensitivity in MKR mice after PPAR $\gamma$ activation despite a reduction of muscle triglyceride content.

While the exact target sites and mechanisms of action of TZDs are not entirely clear, adipose tissue, which expresses a high level of PPAR $\gamma$ [40], is a direct and probably the primary target site for TZD action. TZDs were effective in $o b / o b$ mice without liver $\operatorname{PPAR} \gamma$ and in muscle PPAR $\gamma$-deficient mice $[22,41]$. In the present study, we show a marked improvement in insulin sensitivity in adipose tissue of MKR mice after rosiglitazone treatment. However, whole-body insulin sensitivity and glucose homeostasis were not affected. Moreover, hepatic insulin resistance was not affected in MKR mice after rosiglitazone treatment. Therefore, these results suggest that enhanced insulin action in adipose tissue alone is not sufficient for improvement of whole-body insulin sensitivity.

A recent study [34] demonstrated that TZD treatment of obese Zucker rats resulted in an insulin response in the liver that was much later than that seen in adipose tissue and muscle. Furthermore, no improvement of insulin signalling was seen in primary hepatic cells in culture following TZD treatment, supporting an indirect effect of TZDs on liver function. In support of these results, TZD treatment did not affect hepatic triglyceride content and hepatic insulin sensitivity in MKR mice, regardless of improved insulin action on adipose tissue. Previously, we observed improved whole-body insulin sensitivity and glucose homeostasis with significantly reduced circulating and tissue (liver and muscle) lipid levels of in MKR mice following treatment with WY14,643, a PPAR $\alpha$ agonist [17]. This improvement was associated with sig- nificantly increased insulin sensitivity in adipose tissue and liver. In the present study, rosiglitazone treatment in MKR mice induced significant improvement of insulin sensitivity in adipose tissue but failed to alter hepatic insulin resistance. The lack of EGP suppression during hyperinsulinaemic-euglycaemic clamp analysis and unchanged gene expression of hepatic gluconeogenic enzymes, PEPCK and G-6-P were associated with hepatic insulin insensitivity in MKR mice after treatment. Therefore, a comparison of the results of WY14,643 and rosiglitazone treatment with those of the MKR mice model implicates an important role for hepatic insulin action (endogenous glucose production) in whole-body insulin sensitivity in MKR mice.

Decreased circulating lipid levels were not associated with changes in hepatic triglyceride levels in MKR mice after rosiglitazone treatment. The expression of PPAR $\gamma$ is elevated in steatotic livers of $o b / o b$ and lipodystrophic mice and contributes to triglyceride synthesis and clearance by the liver [42, 43]. Furthermore, insulin increased the expression of the SCD-1 gene, which is involved in synthesis of monounsaturated fatty acid from saturated fatty acyl-CoA [44]. Here, we demonstrated that levels of hepatic PPAR $\gamma$ and SCD-1 mRNA were elevated significantly in MKR mice compared with WT mice. Rosiglitazone treatment in MKR mice did not affect expression of these genes. This may lead to the maintenance of a steatotic liver.

The levels of adiponectin are positively associated with insulin sensitivity in human and animal models $[45,46]$ and are robustly induced after TZD treatment $[47,48]$. However, other clinical studies showed less of a correlation between circulating adiponectin levels and insulin sensitivity in patients after TZD treatment $[2,48]$. A recent study has demonstrated that the oligomeric distribution of circulating adiponectin plays an important role in modulation of its bioactivity to regulate insulin sensitivity in response to TZDs [24]. Furthermore, diabetic patients heterozygous for the G90R mutation at the human adiponectin locus demonstrated a specific decrease in HMW adiponectin [49]. Treatment with TZDs, rosiglitazone and pioglitazone, significantly increased serum adiponectin levels in both WT and MKR mice. A significant increase in the ratio of HMW : total adiponectin paralleled the enhanced increased suppression of endogenous glucose production in WT after TZD treatment. In contrast, MKR mice following TZD treatment failed to show a change in the ratio of HMW : total adiponectin and insulin suppression of endogenous glucose production. TZD treatment has been known to improve hepatic insulin action and the ratio of HMW : total adiponectin was positively associated with improved hepatic insulin sensitivity by TZD treatment [33]. Therefore, the unchanged HMW : total adiponectin ratio may, in part, explain the lack of improvement in 
hepatic insulin sensitivity in MKR mice after TZD treatment. Interestingly, there was a two-fold increase in the HMW : total adiponectin ratio even in 3-weekold MKR mice compared to WT mice, and this improved ratio remained unchanged even at 8 weeks (Fig. 3a). At 3 weeks of age, MKR mice have normal glucose levels and elevated insulin levels, yet the ratio of the adiponectin complexes released by adipocytes is already dramatically altered. MKR mice may therefore represent a unique model in which adipose tissue, despite a significant reduction in insulin sensitivity, is apparently able to mount a compensatory response through altered regulation of adiponectin complex formation and secretion. The fact that adipose tissue responds to insulin resistance in the muscle through altered output of an adipokine at a stage when glucose levels remain relatively normal suggests that altered expression of a muscle-derived factor in MKR mice may be responsible for this response in adipose tissue.

In summary, rosiglitazone and pioglitazone treatments, which led to redistribution of lipids from circulating or local tissue (skeletal muscle) to adipose tissue and possibly liver, and markedly enhanced adipose tissue insulin sensitivity, were not sufficient to improve the hyperglycaemic and hyperinsulinaemic levels in MKR mice. Furthermore, the positive response in adipose tissue failed to affect hepatic insulin resistance in concert with an unchanged HMW : total adiponectin ratio. Thus, these data demonstrate that enhanced insulin action on adipose tissue with PPAR $\gamma$ activation is not able to counterbalance the diabetic nature of MKR mice induced by defective IGF-1/insulin receptor signalling pathways in skeletal muscle. These results suggest that crosstalk between insulinsensitive organs, including adipose, muscle and liver, is critical for normal insulin action and glucose homeostasis.

Acknowledgements. This work was supported in part by a research grant from the American Diabetes Association to D. LeRoith.

\section{References}

1. Kaplan F, Al-Majali K, Betteridge DJ (2001) PPARS, insulin resistance and type 2 diabetes. J Cardiovasc Risk $8: 211-217$

2. Olefsky JM (2000) Treatment of insulin resistance with peroxisome proliferator-activated receptor gamma agonists. J Clin Invest 106:467-472

3. Saltiel AR, Olefsky JM (1996) Thiazolidinediones in the treatment of insulin resistance and type II diabetes. Diabetes 45:1661-1669

4. Bajaj M, Suraamornkul S, Pratipanawatr T et al. (2003) Pioglitazone reduces hepatic fat content and augments splanchnic glucose uptake in patients with type 2 diabetes. Diabetes 52:1364-1370

5. Inzucchi SE, Maggs DG, Spollett GR et al. (1998) Efficacy and metabolic effects of metformin and troglitazone in type II diabetes mellitus. N Engl J Med 338:867-872
6. Maggs DG, Buchanan TA, Burant CF et al. (1998) Metabolic effects of troglitazone monotherapy in type 2 diabetes mellitus. A randomized, double-blind, placebo-controlled trial. Ann Intern Med 128:176-185

7. Mayerson AB, Hundal RS, Dufour S et al. (2002) The effects of rosiglitazone on insulin sensitivity, lipolysis, and hepatic and skeletal muscle triglyceride content in patients with type 2 diabetes. Diabetes 51:797-802

8. Petersen KF, Krssak M, Inzucchi S, Cline GW, Dufour S, Shulman GI (2000) Mechanism of troglitazone action in type 2 diabetes. Diabetes 49:827-831

9. Tontonoz P, Hu E, Spiegelman BM (1994) Stimulation of adipogenesis in fibroblasts by PPAR gamma 2, a lipid-activated transcription factor. Cell 79:1147-1156

10. Okuno A, Tamemoto H, Tobe K et al. (1998) Troglitazone increases the number of small adipocytes without the change of white adipose tissue mass in obese Zucker rats. J Clin Invest 101:1354-1361

11. Moller DE (2001) New drug targets for type 2 diabetes and the metabolic syndrome. Nature 414:821-827

12. Kim JK, Fillmore JJ, Gavrilova O et al. (2003) Differential effects of rosiglitazone on skeletal muscle and liver insulin resistance in A-ZIP/F-1 fatless mice. Diabetes 52:1311-1318

13. Ciaraldi TP, Huber-Knudsen K, Hickman M, Olefsky JM (1995) Regulation of glucose transport in cultured muscle cells by novel hypoglycemic agents. Metabolism 44:976-981

14. Arioglu E, Duncan-Morin J, Sebring N et al. (2000) Efficacy and safety of troglitazone in the treatment of lipodystrophy syndromes. Ann Intern Med 133:263-274

15. Burant CF, Sreenan S, Hirano K et al. (1997) Troglitazone action is independent of adipose tissue. J Clin Invest 100:2900-2908

16. Fernandez AM, Kim JK, Yakar S et al. (2001) Functional inactivation of the IGF-I and insulin receptors in skeletal muscle causes type 2 diabetes. Genes Dev 15:1926-1934

17. Kim, H, Haluzik M, Asghar Z et al. (2003) Peroxisome proliferator-activated receptor-alpha agonist treatment in a transgenic model of type 2 diabetes reverses the lipotoxic state and improves glucose homeostasis. Diabetes 52:1770-1778

18. Kruszynska YT, Olefsky JM (1996) Cellular and molecular mechanisms of non-insulin dependent diabetes mellitus. J Investig Med 44:413-428

19. Jiang, G, Dallas-Yang Q, Li Z et al. (2002) Potentiation of insulin signaling in tissues of Zucker obese rats after acute and long-term treatment with PPARgamma agonists. Diabetes 51:2412-2419

20. Kumar N, Dey CS (2003) Development of insulin resistance and reversal by thiazolidinediones in $\mathrm{C} 2 \mathrm{C} 12$ skeletal muscle cells. Biochem Pharmacol 65:249-257

21. Miyazaki Y, He H, Mandarino LJ, DeFronzo RA (2003) Rosiglitazone improves downstream insulin receptor signaling in type 2 diabetic patients. Diabetes 52:1943-1950

22. Norris AW, Chen L, Fisher SJ et al. (2003) Muscle-specific PPARgamma-deficient mice develop increased adiposity and insulin resistance but respond to thiazolidinediones. J Clin Invest 112:608-618

23. Hevener AL, He W, Barak Y et al. (2003) Muscle-specific PPAR $\gamma$ deletion causes insulin resistance. Nat Med 9:1491-1497

24. Pajvani UB, Du X, Combs TP et al. (2003) Structure-function studies of the adipocyte-secreted hormone Acrp30/adiponectin. Implications for metabolic regulation and bioactivity. J Biol Chem 278:9073-9085

25. Kim JK, Michael MD, Previs SF et al. (2000) Redistribution of substrates to adipose tissue promotes obesity in mice with selective insulin resistance in muscle. J Clin Invest 105:1791-1797 
26. MacLeod JN, Shapiro BH (1988) Repetitive blood sampling in unrestrained and unstressed mice using a chronic indwelling right atrial catheterization apparatus. Lab Anim Sci 38:603-608

27. Rossetti L, Giaccari A (1990) Relative contribution of glycogen synthesis and glycolysis to insulin-mediated glucose uptake. A dose-response euglycemic clamp study in normal and diabetic rats. J Clin Invest 85:1785-1792

28. Youn JH, Kim JK, Buchanan TA (1994) Time courses of changes in hepatic and skeletal muscle insulin action and GLUT4 protein in skeletal muscle after STZ injection. Diabetes 43:564-571

29. Bradley DC, Kaslow HR (1989). Radiometric assays for glycerol, glucose, and glycogen. Anal Biochem 180:11-16

30. Chao L, Marcus-Samuels B, Mason MM et al. (2000) Adipose tissue is required for the antidiabetic, but not for the hypolipidemic, effect of thiazolidinediones. J Clin Invest 106:1221-1228

31. Dupont J, Fernandez AM, Glackin CA, Helman L, LeRoith D (2001) Insulin-like growth factor 1 (IGF-1)-induced twist expression is involved in the anti-apoptotic effects of the IGF-1 receptor. J Biol Chem 276:26699-26707

32. LaCivita KA, Villarreal G (2002) Differences in lipid profiles of patients given rosiglitazone followed by pioglitazone. Curr Med Res Opin 18:363-370

33. Pajvani UB, Hawkins M, Combs TP et al. (2003) Complex distribution, not absolute amount of adiponectin, correlates with thiazolidinedione-mediated improvement in insulin sensitivity. J Biol Chem 279:12152-12162

34. Kramer D, Shapiro R, Adler A, Bush E, Rondinone CM (2001) Insulin-sensitizing effect of rosiglitazone (BRL49653) by regulation of glucose transporters in muscle and fat of Zucker rats. Metabolism 50:1294-1300

35. Smith U, Gogg S, Johansson A, Olausson T, Rotter V, Svalstedt B (2001) Thiazolidinediones (PPARgamma agonists) but not PPARalpha agonists increase IRS-2 gene expression in 3T3-L1 and human adipocytes. FASEB J 15:215-220

36. Qi N, Kazdova N, Zidek V et al. (2002) Pharmacogenetic evidence that $\operatorname{cd} 36$ is a key determinant of the metabolic effects of pioglitazone. J Biol Chem 277:48501-48507

37. Way JM, Harrington WW, Brown KK et al. (2001) Comprehensive messenger ribonucleic acid profiling reveals that peroxisome proliferator-activated receptor gamma activation has coordinate effects on gene expression in multiple insulin-sensitive tissues. Endocrinology 142:1269-1277
38. Seda O, Kazdova L, Krenova D, Kren V (2003) Rosiglitazone fails to improve hypertriglyceridemia and glucose tolerance in CD36-deficient BN.SHR4 congenic rat strain. Physiol Genomics 12:73-78

39. Wilmsen HM, Ciaraldi TP, Carter L, Reehman N, Mudaliar SR, Henry RR (2003) Thiazolidinediones upregulate impaired fatty acid uptake in skeletal muscle of type 2 diabetic subjects. Am J Physiol Endocrinol Metab 285:E354-E362

40. Brun RP, Tontonoz P, Forman BM, Ellis R, Chen J, Evans RM, Spiegelman BM (1996) Differential activation of adipogenesis by multiple PPAR isoforms. Genes Dev 10:974-984

41. Matsusue K, Haluzik M, Lambert G et al. (2003) Liverspecific disruption of PPARgamma in leptin-deficient mice improves fatty liver but aggravates diabetic phenotypes. J Clin Invest 111:737-747

42. Gavrilova O, Haluzik M, Matsusue K et al. (2003) Liver peroxisome proliferator-activated receptor gamma contributes to hepatic steatosis, triglyceride clearance, and regulation of body fat mass. J Biol Chem 278:34268-34276

43. Memon RA, Tecott LH, Nonogaki K et al. (2000) Up-regulation of peroxisome proliferator-activated receptors (PPAR-alpha) and PPAR-gamma messenger ribonucleic acid expression in the liver in murine obesity: troglitazone induces expression of PPAR-gamma-responsive adipose tissue-specific genes in the liver of obese diabetic mice. Endocrinology 141:4021-4031

44. Waters KM, Ntambi JM (1994) Insulin and dietary fructose induce stearoyl-CoA desaturase 1 gene expression of diabetic mice. J Biol Chem 269:27773-27777

45. Berg A H, Combs TP, Scherer PE (2002) ACRP30/ adiponectin: an adipokine regulating glucose and lipid metabolism. Trends Endocrinol Metab 13:84-89

46. Stefan N, Stumvoll M (2002) Adiponectin-its role in metabolism and beyond. Horm Metab Res 34:469-474

47. Combs TP, Wagner JA, Berger J et al. (2002) Induction of adipocyte complement-related protein of 30 kilodaltons by PPARgamma agonists: a potential mechanism of insulin sensitization. Endocrinology 143:998-1007

48. Yu JG, Javorschi S, Hevener AL et al. (2002) The effect of thiazolidinediones on plasma adiponectin levels in normal, obese, and type 2 diabetic subjects. Diabetes 51:2968-2974

49. Waki H, Yamauchi T, Kamon J et al. (2003) Impaired multimerization of human adiponectin mutants associated with diabetes. Molecular structure and multimer formation of adiponectin. J Biol Chem 278:40352-40363 